\title{
A crítica novo-institucionalista ao pensamento da Cepal: a dimensão institucional e o papel da ideologia no desenvolvimento econômico ${ }^{1}$
}

\author{
Hélio Afonso de Aguilar Filho ${ }^{2}$ \\ Edison Benedito da Silva Filho ${ }^{3}$
}

\section{Resumo}

Este trabalho procura discutir a procedência de críticas levantadas por autores da Nova Economia Institucional à explicação da Cepal para as causas do atraso econômico da América Latina. Argumentamos que o pensamento cepalino não negligencia a dimensão institucional do desenvolvimento econômico, nem tampouco se limita a fornecer argumentos para a adoção de políticas econômicas que reforcem a ineficiência da matriz institucional desses países. Enquanto demonstramos a improcedência dessa crítica, evidenciaremos a proximidade do pensamento cepalino em relação ao institucionalismo econômico, e destarte, a viabilidade da construção de uma agenda comum de pesquisa para essas escolas.

Palavras-chave: Conselho Econômico para a América Latina (Cepal); Nova Economia Institucional (NEI); Institucionalismo; Estruturalismo; Teoria da dependência.

\begin{abstract}
The new institutional economics critique on ECLA thought: the institutional dimension and the role of ideology in economic development

This paper aims at discussing the validity of criticism raised by New Institutional Economics against ECLA (or Cepal) explanation of Latin America economic underdevelopment. We shall argue that the cepalista approach neither neglects the institutional dimension of the economic development nor is limited to provide reasoning for the adoption of economic policies that would reinforce the ineffectiveness of the institutional matrix of those countries. While demonstrating that such criticism is misplaced, we shall also emphasize the viability of a common research agenda between ECLA school and economic institutionalism.
\end{abstract}

Key words: Economic Council for Latin America (ECLA); New Institutional Economics (NIE); Institutionalism; Structuralism; Dependence theory.

JEL B15, B25, B31, B52, N16.

\section{Introdução}

Uma vasta literatura econômica tem se dedicado ao estudo dos fatores que explicariam o fracasso econômico da América Latina, especialmente quando

(1) Trabalho recebido em março de 2008 e aprovado em outubro de 2008.

(2) Professor adjunto da Universidade Estadual do Oeste do Paraná (Unioeste-FBE) / Doutor em Economia pela Universidade Federal do Rio Grande do Sul (UFRGS), Porto Alegre, RS, Brasil. E-mail: haaf73@yahoo.com.br.

(3) Técnico de Planejamento e Pesquisa do Instituto de Pesquisa Econômica Aplicada (IPEA), Brasília, DF, Brasil. E-mail: edisonbsilva@yahoo.com.br. 
comparado à experiência recente de outros países periféricos. De fato, o descaminho latino-americano parece se tornar ainda mais paradoxal a partir da constatação de que, até fins do século XVIII, países como Brasil e México ostentavam praticamente a mesma renda per capita que os Estados Unidos da América (Harber, 1997). A busca de uma explicação coerente para a enorme divergência verificada nas trajetórias econômicas desses países ao longo dos últimos séculos constitui um objetivo central no esforço de pesquisa das teorias do desenvolvimento.

$\mathrm{Na}$ análise dos problemas enfrentados pelos países latino-americanos no seu rápido processo de transformação econômica e social, ao longo do século XX, destacam-se duas correntes de pensamento econômico, em virtude tanto da enorme influência que exerceram sobre as políticas adotadas na região quanto das profundas divergências conceituais que as opõem: a escola cepalina ${ }^{4}$ e a chamada Nova Economia Institucional (NEI).

$\mathrm{Na}$ busca pelas raízes históricas do atraso latino-americano, a Cepal se concentrou em analisar como se deu o processo de inserção internacional das excolônias ibéricas a partir do século XIX. Seus autores constataram que a especialização comercial, com foco na produção e exportação de alguns poucos produtos primários, teria sido desfavorável aos países da América Latina, em virtude tanto da tendência à elevação dos preços industriais quanto da depreciação dos produtos primários em decorrência da peculiar estrutura social desses países. A rigidez institucional destes países contribui para a perpetuação de estruturas econômicas arcaicas, que impediriam a disseminação dos ganhos do progresso econômico para as camadas mais empobrecidas da sociedade.

Por achar-se baseada em argumentos que enfatizam a importância do papel desempenhado pela periferia no sistema econômico mundial, em detrimento de fatores internos que historicamente condicionaram sua evolução econômica (em especial suas instituições), a explicação da Cepal para o subdesenvolvimento latino-americano é, no entendimento de North (1991), insatisfatória do ponto de vista científico. O autor acusa esta escola, assim como todas as demais abordagens, de inspiração dependentista, de oferecer teorias que, em essência, consistem de nada mais que racionalizações ad hoc para as causas do atraso das economias latino-americanas. North chega a concluir que a teoria cepalina de fato contribui para a perpetuação do subdesenvolvimento, na medida em que apregoa

(4) Desenvolvida no período pós-guerra por autores vinculados à Comissão Econômica para a América Latina e o Caribe (Cepal), a escola cepalina ainda exerce forte influência no pensamento econômico latinoamericano. Exemplo disso é o surgimento do chamado "neoestruturalismo" a partir da década de 1990, que busca reformular os conceitos originais desenvolvidos pelos teóricos da Cepal através da introdução de novos instrumentos de análise econômica. Para uma síntese dos desenvolvimentos mais recentes do estruturalismo cepalino, ver Bielschowsky (2000). 
uma ideologia intervencionista e contrária à liberdade comercial, cujas implicações econômicas só podem fazer reforçar os efeitos de uma matriz institucional historicamente ineficiente.

Críticas à negligência das instituições por parte dos teóricos dependentistas já foram parcialmente refutadas anteriormente em textos de Cardoso (1977) e Sunkel (1989), os quais demonstraram convincentemente que, no estudo do desenvolvimento, os autores latino-americanos sempre enfatizaram outras dimensões que transcendem a esfera estritamente econômica, com destaque para os fatores sócio-culturais e a herança das instituições coloniais. No entanto, ainda persiste a crítica mais fundamental de North, qual seja, a hipótese de uma influência deletéria do pensamento dependentista sobre a matriz institucional da América Latina. Além disso, as substanciais divergências existentes entre a própria Cepal e os teóricos da dependência demandam um tratamento diferenciado do pensamento cepalino quanto à análise das críticas novo-institucionalistas.

Tomando por referência o instrumental teórico institucionalista, este trabalho busca atingir dois objetivos fundamentais. Em primeiro lugar, demonstraremos que, ao contrário do que afirma a crítica novo-institucionalista, o pensamento cepalino apresenta importantes insights que evidenciam a importância atribuída por esta escola às instituições no desenvolvimento latino-americano. Em segundo lugar, ao evidenciar a proximidade do pensamento da Cepal em relação à tradição do antigo institucionalismo norte-americano, apontaremos a viabilidade de uma agenda de pesquisa comum, que possibilite conjugar as importantes contribuições dessas escolas para o estudo do processo de desenvolvimento econômico das sociedades.

O texto se encontra dividido em três seções fundamentais. A primeira delas discorrerá sobre o referencial teórico institucionalista, estabelecendo a necessária distinção entre as propostas metodológicas do velho e do novo institucionalismo. Na segunda seção, apresentaremos as principais contribuições de North para a teoria do desenvolvimento, bem como sua explicação para as causas do atraso latino-americano. Na terceira seção serão analisados os fundamentos da crítica de North à teoria da dependência em geral e ao pensamento cepalino em particular. A quarta seção se destina a resgatar diversas contribuições do pensamento da Cepal que demonstram a importância atribuída por esta escola ao papel das instituições, destarte procurando refutar o argumento novoinstitucionalista. Por fim, uma vez demonstrada a improcedência de tais críticas no nosso entender, concluiremos que existe uma grande proximidade da teoria cepalina em relação à agenda de pesquisa institucionalista, o que permitiria estabelecer um profícuo diálogo entre essas escolas na busca pela compreensão da natureza dos problemas econômicos enfrentados pela América Latina. 
Hélio Afonso de Aguilar Filho / Edison Benedito da Silva Filho

\section{$1 \mathrm{O}$ velho e o novo institucionalismo econômico}

Embora o estudo das instituições tenha estado presente na literatura econômica desde seus primórdios, o progressivo deslocamento da teoria na direção do formalismo e da abstração próprios da metodologia empregada pelas ciências exatas acabou por relegá-lo a um plano cada vez mais distante. Outrossim, autores que salientavam a importância da matriz institucional para a compreensão da evolução econômica das sociedades, a exemplo de List, Hamilton e os historicistas alemães, ainda exerceriam uma notável influência sobre o pensamento econômico de sua época. Influenciado por essas diferentes matizes, o institucionalismo econômico ganhou força a partir do trabalho de diversos autores norte-americanos no final do século XIX, passando então a constituir um corpo teórico independente, embora ainda destituído do grau de uniformidade analítica que caracteriza as demais correntes da literatura.

De modo a caracterizar o pensamento institucionalista contemporâneo, usualmente se costuma dividi-lo em duas grandes correntes, devido às profundas divergências teóricas que as opõem: o chamado "antigo institucionalismo" (Old Instititutional Economics - OIE) e a Nova Economia Institucional (NEI). A OIE segue a tradição dos primeiros autores institucionalistas, em especial Veblen, Commons, e Mitchell, os quais buscavam analisar os fenômenos econômicos a partir, principalmente, da influência de normas e valores coletivos, da evolução tecnológica e dos condicionantes históricos da sociedade, e utilizando também a contribuição de outras ciências humanas, a exemplo da psicologia e da biologia. Embora longe de constituir uma estrutura coesa de pensamento científico, essa escola foi responsável por expandir definitivamente o escopo da análise econômica, oferecendo toda uma nova perspectiva para a compreensão dos problemas investigados pela economia. Já a NEI, embora assumidamente inspirada pelo antigo institucionalismo, dele se distancia na medida em que busca oferecer instrumentos para a compreensão da influência da matriz institucional sobre o ambiente econômico que estejam baseados nos mesmos fundamentos metodológicos e conceituais que estruturam o pensamento econômico convencional.

\subsection{Divergências entre o velho e o novo institucionalismo}

Segundo Rutherford (1999), os principais pontos de discordância entre o velho e o novo institucionalismo decorrem das opções metodológicas adotadas por essas correntes, que apresentam, respectivamente, as seguintes características gerais: (i) a preferência pela pesquisa histórica e por uma abordagem descritiva, em oposição ao formalismo teórico; (ii) a visão das instituições como moldadoras das preferências individuais, ao invés de exclusivamente moldadas por estas; (iii) o questionamento dos limites da racionalidade individual e a adoção de uma visão 
multidisciplinar para a explicação do comportamento dos agentes, em oposição à aceitação de muitos dos pressupostos da ação racional tal qual encampados pela teoria neoclássica; (iv) a visão das instituições como resultado do planejamento deliberado dos agentes, ao invés de emergentes de uma ordem espontânea surgida no livre mercado; e (v) a atribuição ao Estado de uma maior responsabilidade na busca pelo aprimoramento da sociedade, em oposição à visão crítica do Estado que enfatiza seu caráter opressor da liberdade e perpetuador de ineficiências oriundas do comportamento oportunista dos agentes.

Obviamente, a oposição metodológica apresentada acima não pode ser tomada como um critério absoluto de distinção entre o pensamento dos autores da OIE e da NEI. De fato, são muito mais comuns os casos onde suas ideias se encontram situadas entre esses dois extremos - embora cada autor professe sua convicção na direção de uma dessas concepções teóricas, ele em geral estará disposto a fazer concessões a seus opositores em diversos casos concretos (Rutherford, 1999, p. 4-6). Outrossim, entendemos que a caracterização dessa dicotomia ainda é essencial para a compreensão do pensamento institucionalista em todas as suas dimensões.

\subsection{Complementaridades entre as abordagens institucionalistas}

Não obstante o reconhecimento dessas divergências analíticas, ainda é possível verificar a existência de uma grande complementaridade entre as abordagens da OIE e da NEI. Isso se deve, em particular, ao fato de ambas correntes compartilharem muitos dos mais recentes avanços teóricos no estudo dos fenômenos econômicos, a exemplo das contribuições da teoria schumpeteriana, da escola austríaca e de diversas outras áreas do conhecimento humano, tais como a história, a psicologia, a sociologia e a biologia (Rutherford, 1999, p. 1-4; Hodgson, 1993).

Tanto o velho quanto o novo institucionalismo encampam hipóteses como a racionalidade limitada dos agentes, a influência decisiva de hábitos, normas e valores sociais sobre o comportamento individual, o processo de retroalimentação e de ganhos de escala que assegura a perpetuação de uma matriz institucional ao longo do tempo (efeitos lock-in e path dependence), dentre outros elementos em comum. Pode-se afirmar que as similaridades entre essas correntes não se resumem apenas à ênfase colocada sobre o papel das instituições na economia, pois ambas compartilham da mesma agenda de pesquisa econômica (Rutherford, 1999; Samuels, 1995).

A imensa seara de elementos comuns e dissonantes, que ora aproxima, ora afasta o velho do novo institucionalismo, não compromete, contudo, a eficácia do pensamento institucionalista nem o descaracteriza enquanto corpo teórico 
independente na literatura econômica. Afinal, como bem aponta Samuels (1995), a ampla diversidade conceitual e o intenso debate de ideias que caracterizam a evolução do institucionalismo são antes evidência de sua vitalidade teórica do que de uma eventual fraqueza do ponto de vista da coesão metodológica.

\section{$2 \mathrm{O}$ argumento novo-institucionalista}

North, principal expoente da teoria novo-institucionalista do desenvolvimento, produziu relevantes insights para explicar as divergências no desempenho das economias ao longo do tempo. $\mathrm{O}$ autor ressalta a importância dos incentivos produzidos pela matriz institucional para a redução dos custos de produção e de transação que bloqueiam a plena difusão das relações capitalistas de produção e de troca. ${ }^{5}$ A matriz institucional é concebida como um conjunto de regras, tanto formais quanto informais, bem como suas características de enforcement, que criam os incentivos que moldarão a ação dos agentes individuais e organizações. ${ }^{6} \mathrm{Na}$ sua capacidade de adequação e sustentação do ambiente produtivo se encontraria a chave para a compreensão da existência de diferentes trajetórias de desempenho econômico ao longo da história.

(5) A proposição fundamental da teoria de North é a de que as instituições se formam com diferentes graus de eficiência na promoção da cooperação entre os agentes em cada sociedade (Bueno, 2003). Estes graus de eficiência são determinados, a princípio, pelas soluções encontradas por cada sociedade específica na busca de reduzir os chamados custos de produção e de transação. Os custos de produção envolvem a forma como se estruturam as organizações produtivas e a tecnologia por elas empregada, dependendo em larga medida dos valores e da cultura de cada sociedade. Valores que incentivem a experimentação, a mudança tecnológica e a adoção de novos métodos de produção são responsáveis pela redução destes custos. Já os custos de transação emergem das limitações da capacidade racional dos seres humanos e das incertezas próprias do ambiente econômico, que geram dificuldades para a especificação dos direitos de propriedade. Estes podem ser divididos em dois tipos: os chamados "custos de mensuração", que se relacionam às dificuldades dos agentes em definir claramente o objeto da transação; e os "custos de enforcement", que, por sua vez, referem-se à incerteza que os agentes possuem com relação à propriedade do bem a ser trocado, e, portanto estão relacionados a problemas de legitimidade da transação a ser efetuada (Gala, 2003). Ressalta-se que a redução dos custos de transação pode se dar tanto através do estabelecimento de contratos e distribuição mais eficiente de direitos de propriedades, como por meio de valores historicamente consagrados numa comunidade, a exemplo da valorização do trabalho braçal e da honestidade, permitindo assim a emergência de um intercâmbio mais complexo e produtivo.

(6) Para North (1991), as instituições seriam as regras do jogo em uma sociedade, conformando os incentivos para os agentes e as organizações atuarem na busca de suas finalidades específicas. As instituições, de forma geral, consistem de limitações informais, regras formais e também de suas características de enforcement. As limitações informais incluem as convenções, as normas de comportamento e os códigos de condutas reconhecidos. As regras formais, a princípio, diferem das regras informais apenas em grau; são criadas por decisões de corpos políticos, jurídicos e econômicos, baseadas nos modelos subjetivos dos governantes e daqueles que têm o poder de colocar em pauta, através do Estado, as regras de seus interesses. As características do enforcement são as garantias de cumprimento dessas limitações e regras, bem como dos contratos por elas mediados. Neste caso, destaque especial deve ser dado ao papel do Estado, cuja atuação fornece a base para as transações efetuadas em sociedades complexas baseadas em trocas impessoais. Historicamente, o Estado acaba por se tornar o principal responsável pela distribuição ineficiente dos direitos de propriedade, pois estabelece regras e direitos de propriedade em troca de ingressos fiscais, sem necessariamente guardar um compromisso para com a racionalidade econômica. 
A crítica novo-institucionalista ao pensamento da Cepal: a dimensão institucional e o papel da ideologia...

\subsection{O papel das instituições na promoção da eficiência}

Em sociedades fundadas em densas redes de relações personalistas, a exemplo da América Latina, embora os custos de produção sejam altos, os custos de transação permanecem relativamente baixos. Isso porque os custos de verificação e de garantia dos direitos de propriedade são reduzidos em função do incentivo ao cumprimento dos contratos que decorre do relacionamento pessoal (Fiani, 2002). Nas sociedades economicamente mais complexas, entretanto, os custos de produção são baixos e os custos de transação são altos, pois, em virtude da concorrência e da dominância de relações materiais, não sujeitas a um comprometimento individual de longo prazo, os empreendedores são capazes de empatar um maior volume de capital fixo e se acham estimuladas a investir mais constantemente em inovações tecnológicas. Nestas sociedades, as trocas são impessoais, com o elevado grau de especialização e divisão do trabalho, demandando uma maior intervenção deliberada na formulação de instituições.

Quando discute o problema da eficiência, North também transcende o enfoque estritamente alocativo e de curto prazo que caracteriza a análise neoclássica. Ele aponta a existência de uma modalidade de eficiência distinta da produtiva, a qual denomina adaptativa, e que consiste na capacidade das sociedades se adaptarem às constantes transformações do ambiente econômico, através da inovação tecnológica e da mudança institucional. ${ }^{7}$ Dois fatores são, na visão do autor, imprescindíveis para assegurar essa capacidade no longo prazo: a garantia de liberdades fundamentais e a progressiva elevação do nível educacional da população.

\subsection{Estado, sociedade e path dependence}

Como as fontes do crescimento econômico e também seus custos são derivados dos incentivos estabelecidos pelo marco institucional, arranjos com maior ou menor grau de eficiência podem perdurar em virtude das próprias falhas que caracterizam os mercados políticos, e também porque as instituições possuem

(7) São profundas as implicações desta nova dimensão do conceito de eficiência para aquelas teorias que anteriormente apontavam um único e estritamente determinado fator como responsável pelo processo de desenvolvimento econômico (Engerman; Sokoloff, 2003). Em outras palavras, as instituições importam, mas não existe uma instituição que seja única, específica e insubstituível, e que deva ser replicada em todas as sociedades de modo a assegurar seu crescimento econômico sustentado. Antes, é imprescindível compreender a significância das várias estruturas sociais e culturais que distinguem as sociedades, no intuito de adaptá-las de modo a ampliar suas possibilidades de desenvolvimento. Analisando conjuntamente as noções de eficiência produtiva e adaptativa, podemos concluir, com base na teoria de North, que, embora inexistam modelos ideais e universalmente replicáveis de instituições, existem algumas condições gerais que se fazem necessárias para assegurar a atuação eficiente dos agentes econômicos. A matriz institucional deve oferecer condições para a competitividade e para a tomada descentralizada de decisões, de modo a recompensar a aquisição de habilidades e conhecimentos produtivos, além de especificar e tornar efetivos os direitos de propriedade. 
rendimentos crescentes, caracterizados por uma série de externalidades e complementaridades de rede. A mais importante causa de persistência das instituições reside nas limitações informais, que por natureza evoluem mais lentamente ao longo do tempo. Portanto, devido ao caráter path dependence do processo de mudança institucional, a história importa para o desenvolvimento.

A América Latina constitui, na visão de North (1994), um notório exemplo de persistência de matrizes institucionais ineficientes em razão dos mecanismos de path dependence. A apropriação de ganhos redistributivos, por parte de grupos políticos aferrados ao poder, impede a modernização do aparato institucional, perpetuando a vigência de estruturas de governança centralizadoras e excessivamente burocratizadas, e de fato constituindo um imenso entrave para o desenvolvimento desses países. A reduzida mobilidade social, associada a um elevado grau de rigidez institucional, contribui para a sustentação de elites desprovidas de interesse econômico voltado à produção material e à inovação tecnológica, constituindo também um estímulo à emergência de governos autoritários e de violentos processos de ruptura política. Assim, ao contrário do que afirmam as teorias centradas na hipótese de exploração dos países periféricos, a NEI credita o atraso econômico destes, primordialmente, à histórica ineficiência de suas matrizes institucionais, que impede a consolidação de um ambiente de estabilidade favorável ao pleno desenvolvimento das forças capitalistas.

Nos países anglo-saxônicos, a reação da sociedade à expansão tributária do Estado possibilitou a modernização institucional e a limitação dos poderes da Coroa. Nos países ibéricos, contudo, a tradição absolutista e a ausência de uma resistência articulada de setores da sociedade civil, em virtude da fragmentação política, fizeram com que o Estado acabasse por subjugar e mesmo absorver por completo a esfera privada, moldando-a segundo seus próprios interesses. Tomando um país como exemplo, a saber, o México do século XIX, Coastworth (apud North, 1991, p. 116-117) aponta algumas dessas características deletérias da tradição institucional ibérico:

The interventionist and pervasively arbitrary nature of the institutional environment forced every enterprise, urban or rural, to operate in a highly politicized manner, using kinship networks, political influence, and family prestige to gain privileged access to subsidized credit, to aid various strategems for recruiting labor, to collect debts or enforce contracts, to evade taxes or circumvent the courts, and to defend or assert titles to lands. Success or failure in the economic arena depended on the relationship of the producer with the political authorities (...)

A pauta institucional imposta por Portugal e Espanha às suas colônias segue desempenhando até hoje um papel determinante na evolução econômica destes países. Mesmo após a independência, a centralização e o intercâmbio 
A crítica novo-institucionalista ao pensamento da Cepal: a dimensão institucional e o papel da ideologia...

personalizado continuaram constituindo o bojo das relações sociais nas excolônias. As tentativas de descentralização, por sua vez, redundaram em novos esquemas de reconcentração de poder, com as províncias autodenominadas "federadas" passando a atuar de forma paternal na busca de transferências e regalias do poder central para suas respectivas regiões (Kalmanovitz, 1997).

\subsection{O papel da ideologia e dos modelos mentais}

Ao contrário de outros autores mais próximos da tradição neoclássica, que adotam uma versão mais radical do individualismo metodológico na qual as preferências individuais são tomadas da mesma forma que são dadas, North salienta a importância das instituições como formadoras e perpetuadoras dos interesses individuais. A matriz institucional não se limita a sinalizar aos agentes qual a possibilidade mais vantajosa de ação; ela, de fato, os impele na direção de um determinado padrão de organização econômica vigente, a partir do estabelecimento de crenças, hábitos e valores compartilhados. Daí decorre a importância da cultura e da ideologia enquanto elementos determinantes da trajetória de desenvolvimento das sociedades. Segundo North (1991, p. 111):

Ideas and ideologies matter, and institutions play a major role in determining just how much they matter. Ideas and ideologies shape the subjective mental constructs that individuals use to interpret the world around them and make choices. Moreover, by structuring the interaction of human beings in certain ways, formal institutions affect the price we pay for our actions, and to the degree the formal institutions are deliberately or accidentally structured to lower the price of acting on one's ideas, they provide the freedom to individuals to incorporate their ideas and ideologies into the choices they make.

O reconhecimento da importância da ideologia e da cultura enquanto elementos capazes de moldar as preferências individuais não implica assumir a matriz institucional como dada ou subestimar a capacidade dos agentes transformarem conscientemente as instituições segundo seus próprios objetivos. $\mathrm{O}$ que o autor ressalta, aqui, é a necessidade de considerar, para o entendimento da evolução das sociedades, o impacto dos modelos mentais compartilhados no direcionamento da ação individual, que fica ainda mais evidente quando analisado o custo econômico do desvio em relação aos padrões de comportamento historicamente consolidados.

\section{A crítica novo-institucionalista ao pensamento cepalino}

A crítica de North ao pensamento da Cepal consiste de dois argumentos fundamentais. Em primeiro lugar, o autor sustenta que a análise estruturalista em geral, característica do pensamento cepalino, negligencia a influência da formação institucional dos países latino-americanos sobre seu desenvolvimento econômico, 
tomando como dada e irreversível sua posição periférica no comércio internacional. Em segundo lugar, sugere-se que a ideia de dependência, adotada tanto por autores cepalinos quanto marxistas e outros vinculados ao estruturalismo, ${ }^{8}$ pressupõe uma relação de dominação econômica e política que se faz imposta pelas economias centrais, não derivando, portanto, de qualquer tipo de característica intrínseca das economias periféricas. Segundo o autor (North, 1991, p. 99-100),

(...) both the writings of the Economic Commission for Latin America (ECLA) and dependency theory explain the poor performance of Latin American economies on the basis of the international terms of trade with industrial countries and other conditions external to those economies. Such an explanation not only rationalizes the structure of Latin American economies, but also contains policy implications that would reinforce the existing institutional framework.

Em outras palavras, critica-se a Cepal por utilizar um elemento exógeno e ad hoc para explicar o atraso latino-americano e, destarte, justificar as políticas econômicas populistas implementadas ao longo do século XX na América Latina, o que afinal evidenciaria seu viés ideológico e a fragilidade de suas construções teóricas. Trata-se, portanto, de uma crítica fundamental, completamente diversa daquela levantada por autores neoclássicos, que se limitavam a testar as hipóteses cepalinas de deterioração dos termos de troca e de barreiras à transferência de tecnologia para os países periféricos. Como os modelos mentais construídos pelos agentes econômicos influenciam decisivamente as trajetórias desenvolvimento, o autor acusa os teóricos cepalinos, bem como os da dependência, não apenas de estarem equivocados quanto às causas do subdesenvolvimento latino-americano, mas - o que é ainda mais grave - de contribuírem para reforçar esse atraso, na medida em que alimentam uma ideologia antiliberal que mascara as contradições internas desses países e justifica as relações de poder estabelecidas pelo status quo político (North, 1991).

(8) Embora o conceito de dependência ainda seja frequentemente utilizado de maneira ambígua ou excessivamente limitada, é inegável sua importância para a compreensão da dimensão institucional da trajetória econômica da América Latina, na medida em que permite analisar de forma conjunta as diferentes contradições existentes nos âmbitos interno e externo dessas economias. Contudo, devido à sua imprecisão teórica e às grandes divergências metodológicas existentes entre os teóricos que utilizam tal conceito, torna-se extremamente difícil caracterizar uma escola de pensamento econômico dependentista, tal como fazem diversos autores novosinstitucionalistas. Em particular, é preciso distinguir os autores marxistas, que em geral empregam o conceito de dependência numa ótica mais restrita, subordinada à lógica do capitalismo expressa na divisão internacional do trabalho, de outros que possuem uma visão mais favorável da sociedade capitalista e que, destarte, optam por aplicar o conceito de dependência num enfoque ampliado, apontando assimetrias de poder internas às economias periféricas e com uma dinâmica mais independente em relação às transformações das economias centrais. Para uma síntese dessas divergências e de suas consequências para as críticas dirigidas à teoria da dependência, ver Cardoso (1977). 
A crítica novo-institucionalista ao pensamento da Cepal: a dimensão institucional e o papel da ideologia...

\subsection{Crítica à negligência das instituições no pensamento dependentista e cepalino}

Para a compreensão da natureza da crítica novo-institucionalista, cumpre estabelecer com precisão quais os critérios analíticos empregados pelos autores da NEI para embasar seu argumento quanto à suposta negligência da matriz institucional nos modelos dependentistas e cepalinos. Em essência, tais modelos atribuem as causas do atraso latino-americano à relação de dependência estabelecida entre centro e periferia, na qual a América Latina e as demais excolônias europeias ocupam uma posição passiva e necessariamente submissa à lógica ditada pela evolução tecnológica dos países industrializados.

Os autores novos-institucionalistas não negam o papel passivo imposto pela divisão internacional do trabalho aos países periféricos, nem tampouco os problemas oriundos da especialização produtiva em setores de baixo dinamismo tecnológico. Sua crítica se dirige não ao diagnóstico cepalino dos sintomas do atraso, mas sim de suas origens: a NEI busca na própria evolução histórica da matriz institucional latino-americana a chave para compreender sua condição atual de subdesenvolvimento. Nas palavras de North (1991, p. 117):

The divergent paths established by England and Spain in the New World have not converged despite the mediating factors of common ideological influences. In the former, an institutional framework has evolved that permits the complex impersonal exchange necessary to political stability and to capture the potential economic gains of modern technology. In the latter, personalistic relationships are still the key to much of the political and economic exchange. They are a consequence of an evolving institutional framework that produces neither political stability nor consistent realization of the potential of modern technology.

Por tudo isso, tais autores consideram equivocado atribuir o atraso da periferia ao seu papel desempenhado no comércio internacional ao longo da história. Tampouco é consistente o argumento de exploração, por parte de Portugal e Espanha, como causa fundamental do empobrecimento da América Latina. A influência mais deletéria das metrópoles ibéricas sobre a evolução de suas colônias não foi a drenagem de suas riquezas - pois o crescimento econômico não deriva do acúmulo de capital físico, e sim do progresso tecnológico. De fato, na visão desses autores, o maior mal causado pela "trajetória ibérica" teria sido a consolidação de um marco institucional sobejamente ineficiente nesses países, impedindo assim sua modernização econômica.

\subsection{Crítica à ideologia cepalina}

A crítica de North à ideologia que embasa o pensamento cepalino obviamente não se dirige aos resultados imediatos das políticas encampadas pela 
Cepal ou sua racionalidade em termos de eficiência econômica. Na verdade, o autor questiona as consequências a longo prazo da aceitação, por parte da sociedade, de um ideário intervencionista e antiliberal, calcado na ideia de superação da suposta condição de subordinação econômica dos países atrasados em relação aos mais ricos. Os grupos de interesse que detêm o poder na América Latina se acham empenhados em preservar a estrutura institucional vigente de modo a proteger seus ganhos econômicos, e acabam por fazer uso dessa ideologia em seu próprio proveito, acentuando assim a ineficiência das instituições locais. Segundo North (1991, p. 99),

[T] he increasing returns characteristic of an initial set of institutions that provide disincentives to productive activity will create organizations and interest groups with a stake in the existing constraints. They will shape the polity in their interests. Such institutions provide incentives that may encourage military domination of the polity and economy, religious fanaticism, or plain, simple redistributive organizations (...). The subjective mental constructs of the participants will evolve an ideology that not only rationalizes the society's structure but accounts for its poor performance.

Como os agentes compartilham modelos mentais que condicionam, em última análise, grande parte de suas decisões, existe o risco de que o intervencionismo estatal e a rejeição do livre comércio, enquanto oportunidade de desenvolvimento, acabem por incutir nos indivíduos valores e objetivos opostos àqueles característicos de uma sociedade progressista. Inúmeros exemplos históricos ilustram como o fortalecimento de valores nacionalistas e coletivistas pode degenerar em supressão da democracia, xenofobia, protecionismo, aversão à mudança institucional e ao progresso tecnológico, etc.

A hipótese de que os modelos mentais compartilhados desempenham um papel determinante na formação das preferências individuais traz importantes consequências para o estudo do desenvolvimento e da mudança institucional nas sociedades. Em particular, salienta-se o fato de que mesmo os agentes que buscam reformar a estrutura econômica vigente têm sua ação restringida pela influência dos modelos mentais por eles herdados (North, 2005). Isso ajuda a explicar porque políticas e instituições que se mostraram bem-sucedidas em alguns países não podem ser replicadas em outros, nos quais o comprometimento dos agentes para com a mudança é menor em função de sua ideologia e de seus interesses pessoais.

\section{Institucionalismo e ideologia no pensamento da Cepal}

É inegável que as ideias da Cepal tiveram uma influência decisiva sobre as políticas de desenvolvimento adotadas pelos países da América Latina ao longo da segunda metade do século XX (Bustelo, 1998). O longo período de crescimento 
experimentado por essas economias, especialmente após o término da Segunda Guerra Mundial, pode ser em grande parte creditado ao sucesso das políticas de substituição de importações e de promoção da industrialização através de forte intervencionismo estatal, constituindo nitidamente uma estratégia de inspiração cepalina. Contudo, o esgotamento desse modelo de industrialização a partir da década de 1980 precipitou um intenso debate teórico quanto à sua viabilidade no longo prazo e mesmo quanto ao seu apregoado sucesso nas décadas precedentes.

O pensamento desenvolvido pela Cepal preocupou-se fundamentalmente em ressaltar as especificidades dos países latino-americanos, o que por sua vez também demandou uma análise mais detida da evolução histórica de suas instituições e das relações econômicas desses países com o restante do mundo. $\mathrm{O}$ ponto de partida desta reflexão, segundo Bustelo (1998), foi uma profunda insatisfação com a teoria econômica dominante, considerada inadequada para a explicação da trajetória de desenvolvimento dos países periféricos ao longo da história.

\subsection{Fundamentos do estruturalismo cepalino}

O estruturalismo da Cepal assenta-se sobre três premissas fundamentais. Em primeiro lugar, as economias do centro e da periferia são fundamentalmente distintas: enquanto o centro se distingue pela diversificação produtiva e por um elevado grau de homogeneidade social, a periferia apresenta uma estrutura socialmente heterogênea e economicamente especializada. Segundo Bielschowski (2000), a especialização produtiva da periferia se consolida historicamente com as seguintes características: (i) baixo grau de diversificação de sua pauta de exportações, composta essencialmente de produtos primários; (ii) ausência de diversificação horizontal e complementaridade setorial na indústria; (iii) integração vertical; (iv) presença de setores exportadores modernos na forma de enclaves; e (v) demanda por bens manufaturados cujo abastecimento se dá exclusivamente através de importações.

Em segundo lugar, tais estruturas desenvolvem uma relação de dependência regida pela divisão internacional do trabalho. Por dependência, compreende-se uma relação de necessária hierarquia entre dois polos de uma mesma estrutura. Embora mutuamente condicionados, o desenvolvimento de um desses polos se acha inescapavelmente subordinado às condições impostas pelo outro, em função da liderança tecnológica deste. Desenvolvimento e subdesenvolvimento são, portanto, processos diretamente relacionados, já que centro e periferia desempenham funções distintas e complementares no sistema econômico mundial. Não se pode, portanto, dissociar o processo de evolução das 
estruturas econômicas destes países de seu papel enquanto polos num sistema dual, no qual evoluem de forma conjunta e mutuamente determinada. ${ }^{9}$

Por fim, em terceiro lugar, uma vez que reproduzem a disparidade existente entre suas estruturas produtivas, as relações comerciais entre centro e periferia de fato contribuem para reforçar o subdesenvolvimento. Em outras palavras, ao contrário do que afirma a consagrada teoria ricardiana, o livre comércio acentua as desigualdades entre as nações, pois permite que o centro se aproprie dos frutos do progresso técnico obtidos na periferia. Isso porque a maior capacidade de mobilização política dos trabalhadores e empresários nos países desenvolvidos impede que os aumentos de produtividade ali obtidos se traduzam em menores preços para a periferia, sendo ao invés disso apropriados na forma de maiores rendimentos para esses agentes; além disso, a desvalorização dos produtos primários, que ocorre pari passu ao aumento dos preços dos importados em função da peculiar estrutura social dos países periféricos, ${ }^{10}$ impede que estes tenham um aumento suficiente da produtividade do trabalho que lhes permitisse ampliar sua capacidade de poupança e acumulação (Bustelo, 1998).

\subsection{Elementos institucionalistas presentes no pensamento da Cepal}

A abordagem empregada pelos teóricos da Cepal possui uma dimensão necessariamente histórica, com ênfase na análise da evolução institucional dos países latino-americanos e nos efeitos de suas contradições sociais. Pode-se mesmo afirmar que do enfoque histórico-estruturalista cepalino deriva um método de produção científica profundamente atento para o comportamento dos agentes sociais e para a trajetória das instituições ao longo da história (Bielschowsky, 2000). O estruturalismo cepalino, de acordo com Bustelo (1998), não se detém apenas na análise da dimensão histórica dos fenômenos econômicos, mas procura também dar ênfase às questões institucionais, com uma abordagem holística, observando a importância das preferências individuais e da cultura para a consolidação de sua condição periférica.

Para compreender o papel desempenhado pelas instituições no pensamento cepalino, devemos, em primeiro lugar, salientar a distinção existente entre o estruturalismo original da escola estruturalista francesa e o estruturalismo desenvolvido pela Cepal. Este não guarda uma identificação completa com aquele,

(9) É importante ressaltar que a relação de dependência não se acha restrita ao âmbito das relações de troca da periferia, mas também se faz presente na organização interna dessas economias, através da consolidação de toda uma superestrutura institucional que justifica e conserva as relações de produção existentes na infraestrutura primário-exportadora.

(10) Essa peculiaridade reside, de um lado, na abundância relativa de mão-de-obra disponível, que gera aumentos de salários menores do que a produtividade, e, de outro, na existência de elites locais que possuem elevado grau de propensão a consumir e de elasticidade-renda de importações. Esses fatores também contribuem para a progressiva deterioração dos termos de troca no comércio internacional. Ver Bustelo (1998). 
cuja orientação básica consistiu em privilegiar o eixo das sincronias na análise socioeconômica, construindo a partir daí uma sintaxe das disparidades nas organizações sociais. Já o estruturalismo cepalino empenhou-se em destacar a importância dos parâmetros não-econômicos dos modelos macroeconômicos, analisando assim os efeitos engendrados pelas características institucionais das economias periféricas. Segundo Love (2005, p. 100):

Latin American structuralists sought to move economic history beyond a description of economic configurations, flows, and flux to a more analytic treatment of critical structures - both dynamic and relatively static elements in the economic ensemble - that underlay long-term performance as well as cyclical patterns. That is, they sought to specify those structures that had contributed to economic development and those which had impeded it.

Como o comportamento das variáveis econômicas depende em grande medida das características destes parâmetros não-econômicos, consequentemente podemos concluir que "o estruturalismo é um enfoque orientado pela busca de relações diacrônicas, históricas e comparativas" (Bielschowsky, 2000, p. 21). A própria noção de subdesenvolvimento só se faz compreensível para a Cepal enquanto fenômeno histórico e derivado do processo de evolução institucional. Nas palavras de Furtado (1983, p. 43):

O subdesenvolvimento é, portanto, um processo histórico autônomo, e não uma etapa pela qual tenham, necessariamente, passado as economias que já alcançaram um grau superior de desenvolvimento.

Os autores cepalinos jamais consideraram o atraso econômico da América Latina como uma condição inescapável ou uma mera consequência da evolução natural do capitalismo. Ao contrário, seu esforço consistiu justamente em buscar elementos característicos dessas economias que explicassem sua condição de subdesenvolvimento. ${ }^{11}$

(11) Devemos asseverar que o próprio conceito de dependência não implica uma mera constatação da realidade imposta pela história aos países latino-americanos. Ao contrário, ele corresponde a uma relação dialética que se manifesta em diferentes esferas, tanto no âmbito econômico do comércio internacional e das relações de produção existentes nos países periféricos, quanto no âmbito político dos conflitos de classe e do papel do Estado nessas economias (Cardoso, 1974). Essa relação de dominação econômica se consolida no bojo da expansão capitalista para os países periféricos, o que evidencia a importância de sua dimensão institucional, na medida em que é moldada pela própria participação dos atores nacionais envolvidos no processo de transformação econômica. Além disso, a relação de dependência não se consolida de forma unidirecional - em certo sentido, pode-se mesmo afirmar que também os países centrais são "dependentes" em relação aos periféricos, na medida em que se encontram cada vez mais sujeitos aos efeitos de restrições na oferta de produtos primários indispensáveis ao funcionamento de suas economias. Assim, as relações econômicas e sociais estabelecidas entre centro e periferia evoluem ao longo do tempo e adquirem uma nova dimensão na medida em que se mostram cada vez mais evidente a complementaridade e a mútua dependência de suas estruturas produtivas. 
Sunkel (1989) encontra diversas similaridades entre o instrumental teórico do antigo institucionalismo (OIE) e o projeto de pesquisa cepalino. Segundo o autor, em ambas correntes de pensamento econômico

(...) el proceso económico no se considera como un mecanismo estático, circular, reiterativo y equilibrante, limitado principalmente a lo que sucede en los diversos mercados, sino como un proceso evolucionario y socio histórico en marcha, causa y efecto acumulativos de conflictos y cambios en las fuerzas económicas, sociales, culturales y políticas. Los individuos no se equiparan a computadores programados para maximizar una función de bienestar, dentro de determinadas limitaciones; y las empresas tampoco se consideran como computadores programados para maximizar las utilidades, dentro de una función de producción y ciertas restricciones financieras. Se conciben como entidades sociales y culturales, relativamente autónomas pero institucional y estructuralmente configuradas y circunscritas en lo que respecta a valores, normas, comportamientos, formas de asociación y organización (Sunkel, 1989, p. 150).

É fundamental considerar a influência dos fatores não-econômicos na análise histórica de sistemas sociais que se caracterizam por um profundo grau de heterogeneidade econômica e tecnológica, como no caso das economias subdesenvolvidas. Por exemplo, sem um estudo aprofundado da estrutura agrária desses países não é possível explicar a tendência à concentração da renda ocorrida durante a fase de industrialização, nem a rigidez da oferta de alimentos geradora de pressões inflacionárias. Sem uma percepção clara das características da industrialização tardia, não é possível entender a "inadequação tecnológica" que gera o desemprego e a subutilização da mão-de-obra. Segundo Furtado (1997, p. 17-18, grifo nosso):

Como fatores não-econômicos - regime de propriedade da terra, controle das empresas por grupos com visão transnacional dos investimentos, permanência de grande parte da mão-de-obra fora dos mercados organizados, etc. - integram a matriz estrutural do modelo com que trabalha o economista, ao darmos ênfase ao estudo de tais parâmetros fomos chamados de estruturalistas. Em certo sentido, os estruturalistas retomaram a tradição do pensamento marxista, na medida em que este colocou em primeiro plano a análise das estruturas sociais para compreender o comportamento dos agentes econômicos.

A crítica cepalina ao modelo historicamente consolidado de inserção da América Latina no comércio internacional não implica, em absoluto, atribuir a esse modelo a causa do atraso da região, mas sim a perceber nele um instrumento de manutenção do subdesenvolvimento. As soluções apontadas pelos autores da Cepal a diversos problemas econômicos enfrentados pela região necessariamente implicavam uma urgente e profunda transformação das instituições desses países (Street; James, 1982).

Não se sustenta, portanto, a crítica novo-institucionalista à suposta negligência da Cepal no tratamento dos elementos institucionais que 
condicionaram o desenvolvimento das economias latino-americanas. Aliás, tal negligência seria antes cometida pela própria NEI, na medida em que o individualismo metodológico por ela adotado exige o tratamento de conjuntos sociais (tais como países e regiões) como unidades isoladas e independentes do sistema que as envolve. Neste caso, a análise das assimetrias de poder permanece necessariamente limitada às instituições do sistema econômico nacional ora analisado, o que impede o reconhecimento das relações de dominação exteriores a este sistema (Velasco; Cruz, 2003, p. 119). Isso nos ajuda a compreender um aparente paradoxo da teoria de North: ao mesmo tempo em que o autor reconhece e enfatiza a importância das relações de dominação existentes nas sociedades atrasadas enquanto elementos que impedem a modernização de suas instituições, ele, surpreendentemente, desconsidera a influência econômica e ideológica das relações de poder historicamente consolidadas entre esses países e o mundo industrializado.

\subsection{A ideologia cepalina}

A ideologia da Cepal não pode ser dissociada da ideia central de industrialização. A industrialização era defendida não apenas como meio de superação do modelo primário-exportador, mas, sobretudo, como um instrumento necessário para a modernização institucional (Bielschowsky, 2000). E, na ausência de uma burguesia comprometida com a mudança, caberia naturalmente ao Estado a responsabilidade por capitanear o processo de transformação econômica nos países latino-americanos (Cardoso, 1974; Bustelo, 1998). Segundo Love (1996, p. 208):

The central issue that economic theory and ideology addressed in Latin America in the period after 1930 was industrialization, both as a fact (at first a consequence of the decline of export-led growth) and as desideratum (for ECLA, at least at the outset, a 'solution' to the problem of economic underdevelopment).

A análise da Cepal não negligenciou o papel das restrições informais no processo de desenvolvimento econômico: isso é evidenciado pelo fato de seus autores defenderem a urgência de uma profunda transformação do arcabouço institucional existente na América Latina, ao mesmo tempo em que denunciavam o caráter perverso da consolidação de ideologias contrárias aos valores e crenças que constituem a identidade dessas nações (Sunkel, 1989). O fato de essa escola privilegiar a análise das estruturas sociais em detrimento do comportamento individual tampouco implica a negação da influência dos microincentivos sobre os objetivos e a ação dos agentes, pois de acordo com Graciarena (2000, p. 705):

Os indivíduos e grupos, suas vidas e suas necessidades, têm peso, para além de sua condição de 'portadores da estrutura' e de meros agentes passivos da história. Por sua vez, tanto esta quanto a estrutura são mais do que contextos que condicionam o 
conjunto de alternativas, porque (...) numa situação nacional, historicamente concreta e condicionada, há sempre mais de uma alternativa possível.

Se o pensamento cepalino reconhece o papel dos modelos mentais compartilhados enquanto condicionantes fundamentais do comportamento dos agentes econômicos, resta saber se ele, intencionalmente ou não, foi de fato responsável por impingir uma ideologia que justificasse a manutenção da sobejamente ineficiente matriz institucional latino-americana. Curiosamente, algumas das primeiras e mais contundentes críticas à escola cepalina foram provenientes dos próprios teóricos da dependência, em especial daqueles de inspiração marxista. Estes autores eram céticos quanto à capacidade do Estado de conciliar os interesses das burguesias latino-americanas em prol do desenvolvimento econômico (Cardoso, 1974). De fato, o fracasso da democracia a partir do final da década de 50 e a emergência de regimes ditatoriais em praticamente todos os países da região na época parecem corroborar essa visão pessimista, evidenciando o equívoco da ideologia cepalina quanto à capacidade desses países superarem a condição de atraso por suas próprias forças. Conforme Love (1996, p. 273),

Prebisch's terms-of-trade thesis and other pro-industrialization arguments had initially provided ideological support - intentionally or not - for Latin America's national bourgeoisies. Yet by the latter 1960s it was questionable whether that class could achieve the historical project which Prebisch had envisioned.

Não obstante o fracasso da Cepal em incutir uma mentalidade modernizadora na burguesia latino-americana, Love (1996, p. 269-274) conclui que sua ideologia foi capaz de condicionar decisivamente o pensamento da burocracia estatal em prol do progresso econômico. Em diversos países da região, determinados segmentos da administração pública foram capazes de adquirir autonomia frente à influência de grupos de interesse, exercendo suas tarefas segundo critérios coerentes com os requisitos da eficiência econômica e consolidando assim uma esfera privilegiada de influência política. ${ }^{12} \mathrm{O}$ relativo sucesso desses setores na promoção do desenvolvimento ajuda, inclusive, a explicar a persistência da tradição de um elevado grau de intervencionismo estatal na região (Love, 1996).

\section{Considerações finais}

As principais críticas de North a Cepal são: em primeiro lugar, a de que ela negligencia a influência da formação institucional dos países latino-americanos sobre seu desenvolvimento econômico, tomando como dada e irreversível sua

(12) Para uma discussão mais aprofundada sobre a importância do papel desempenhado pela ideologia da burocracia estatal na promoção do progresso econômico, bem como uma análise comparativa entre os diferentes modelos da administração pública adotados pelos países em desenvolvimento, ver Evans (1995). 
posição periférica no comércio internacional; em segundo lugar, sugere-se que a ideia de dependência, introduzida pelo estruturalismo cepalino, pressupõe uma relação de dominação econômica e política que se faz imposta pelas economias centrais, não derivando, portanto, de qualquer tipo de característica intrínseca das economias periféricas. Em outras palavras, o autor acusa a Cepal de utilizar um elemento exógeno e ad hoc para explicar o atraso latino-americano e, destarte, justificar as políticas econômicas populistas implementadas ao longo do século XX em praticamente todo o continente - o que, de resto, evidenciaria o viés ideológico e a fragilidade das construções teóricas cepalinas.

Consideramos, entretanto, improcedentes tais observações. Com respeito à negligência dos aspectos institucionais do desenvolvimento, pode-se argumentar em defesa dos autores cepalinos que estes sempre realçaram a importância dos parâmetros não-econômicos em seus modelos, principalmente quando aplicados à macroeconomia. O estruturalismo presente na abordagem da Cepal não se resume, de modo algum, a um modelo determinístico de explicação do empobrecimento da periferia com base na deterioração dos termos de troca, destarte negligenciando sua evolução institucional. Ao contrário, ao apontar a heterogeneidade social e tecnológica dos sistemas econômicos periféricos, a teoria cepalina de fato enfatiza a influência das raízes institucionais para a explicação das trajetórias de desenvolvimento das sociedades ao longo da história.

Tampouco nos parece justificada a crítica novo-institucionalista à ideologia cepalina. Não é possível contemplar nesta última qualquer compromisso de manutenção do status quo político e institucional, nem tampouco se percebe qualquer incentivo à passividade individual ou à rejeição de valores democráticos e liberais. Pelo contrário, é possível depreender, do pensamento da Cepal, uma visão até excessivamente otimista quanto à vontade modernizadora das burguesias latino-americanas, à habilidade política de seus governos e à capacidade desses países superarem sua condição de subdesenvolvimento por meio de suas próprias forças.

É inegável a importância atribuída pela análise estruturalista ao papel das instituições na promoção do desenvolvimento econômico. O pensamento cepalino conjuga de maneira coerente, em sua análise, tanto a dimensão holística como a histórica, as quais o dotam de suficiente flexibilidade para a aplicação aos mais diversos casos específicos, mantendo, não obstante, a necessária coerência lógica com suas hipóteses mais gerais. Seu arcabouço teórico permite agregar importantes características institucionais presentes nas economias periféricas, sem, contudo, redundar numa análise funcionalista ou excessivamente reducionista, contrariando o instrumental novo-institucionalista, cuja aplicação ao estudo dos problemas econômicos da América Latina tem se mostrado problemática, dada a negligência de fatores culturais na formação das preferências individuais e a 
Hélio Afonso de Aguilar Filho / Edison Benedito da Silva Filho

negação do papel histórico de condicionantes externos a essas economias. De fato, constatamos que, ao mesmo tempo em que se distancia do instrumental teórico da NEI, o pensamento cepalino se aproxima cada vez mais do programa de pesquisa institucionalista consagrado na tradição da OIE. A exploração dos vínculos analíticos existentes entre essas escolas certamente nos propiciará uma inestimável contribuição para o entendimento mais profundo dos problemas latino-americanos.

\section{Referências bibliográficas}

BIELCHOWSKY, Ricardo. Cinquenta anos de pensamento na CEPAL - Uma resenha. In: BIELCHOWSKY, Ricardo (Org.). Cinquenta anos de Pensamento na Cepal. Rio de Janeiro: Record, 2000.

2000.

(Org.). Cinquenta anos de pensamento na Cepal. Rio de Janeiro: Record,

BETHELL, Leslie (Ed.). Ideas and ideologies in Twentieth century Latin América. Cambridge: Cambridge University Press, 1996.

BUENO, Newton Paulo. A nova economia institucional e a historiografia clássica do período colonial brasileiro. ABPHE, Caxambú-MG, 2003.

BURGEÑO, Oscar; RODRIGUES, Octavio. Desenvolvimento e cultura: notas sobre o enfoque de Furtado. 2003. Mimeografado.

BUSTELO, Pablo. Teorías contemporáneas del desarrollo económico. Madrid: Editora Síntesis, 1998.

CARDOSO, Fernando H. The consumption of the dependency theory in the United States. Latin American Research Review, v. 12, n. 3, p. 7-24, 1977.

Notas sobre el estado actual de los estudios sobre dependencia. In: SERRA, José (Org.). Desarrollo latinoamericano: ensayos críticos. Ciudad de México: Fondo de Cultura Económica, 1974, p. 325-356.

COASTWORTH, John H. Structures, endowments, and institutions in the economic history of Latin America. Latin American Research Review, v. 40, n. 3, p. 126-144, 2005.

CONCEIÇÃO, Octavio Augusto C. Os antigos, os novos e os neo-institucionalistas: há convergência teórica no pensamento institucionalista? Revista Análise Econômica, Porto Alegre, ano 19, n. 36, set. 2000.

ENGERMAN, Stanley L.; SOKOLOFF, Kenneth L. Institutional and non-institutional explanations of economic differences. National Bureau of Economic Research, Cambridge, Sept. 2003.

EVANS, Peter B. Embedded autonomy: states and industrial transformation. Princeton: Princeton University Press, 1995.

FIANI, Ronaldo. Crescimento econômico e liberdade: a economia política de Douglass North. Economia e Sociedade, Campinas, v. 11, n. 1, 2002.

FURTADO, Celso. Celso Furtado: economia. OLIVEIRA, Francisco de; FERNANDES, Florestan (Org.). São Paulo: Editora Ática, 1983. 
GALA, Paulo. A teoria institucional de Douglass North. Revista de Economia Política, São Paulo, v. 23, n. 90, abr./jun. 2003.

GRACIARENA, Jorge. Poder e estilos de desenvolvimento: uma perspectiva heterodoxa. In: BIELCHOWSKY, Ricardo. Cinquenta anos de pensamento na Cepal. Rio de Janeiro: Record, 2000, p. 685-714.

GUEDES, Sebastião N. R. Observações sobre a economia institucional: há possibilidade de convergência entre o velho e o novo institucionalismo? In: ENCONTRO NACIONAL DE ECONOMIA POLÍTICA, 5, Fortaleza, 2000.

HARBER, Stephen. How Latin America fell behind: essays on the economic histories of Brazil and Mexico (1800-1914). Stanford, CA: Stanford University Press, 1997.

HARRISS, John; HUNTER, Janet; LEWIS, M. Colin. The new institutional economics in third world development. New York: Routledge, 1997.

HODGSON, G. M. Institutional economics: surveying the 'old' and the 'new'. Metroeconomica, v. 44, n. 1, p. 1-28, Feb. 1993.

HOUNIE, Adela; PITTALUGA, Lucía; PORCILE, Gabriel; SCATOLIN, Fábio. La Cepal y las nuevas teorías del crecimiento. Revista de la Cepal, Santiago de Chile, n. 68, ago. 1999.

KALMANOVITZ, Salomón. Las instituciones, la ley y el desarrollo económico en Colombia. Bogotá: Banco de la República, Feb. 1997. (Serie Borradores de Economía, n. 69).

. La cliometría y la historia económica institucional: reflejos latinoamericanos. contribuciones a la economía. Colombia. Disponível em: <http://www.eumed.net/ce/skclio.htm>. Acesso em: 2006.

LEWIS, Colin M. States and markets in Latin America: the political economy of economic interventionism. London School of Economics, Jan. 2005. (Working Paper, n. 09/05).

LOVE, Joseph L. Economic ideas and ideologies in Latin America since 1930. In: BETHELL, Leslie (Ed.). Ideas and ideologies in Twentieth Century Latin América. Cambridge: Cambridge University Press, 1996.

Structuralism and dependency in peripheral Europe: Latin American ideas in Spain and Portugal. Latin American Research Review, v. 39, n. 2, p. 114-140, 2004.

The rise and decline of economic structuralism in Latin America: new dimensions. Latin American Research Review, v. 40, n. 3, p. 100-125, 2005.

MÉNARD, Claude; SHIRLEY, Mary M. (Ed.). Handbook of new institutional economics. Netherlands: Springer, 2005.

NORTH, Douglass C. Institutions, institutional change and economic performance. New York: Cambridge University Press, 1991.

Economic performance through time. American Economic Review, v. 84, p. 359-368, Alfred Nobel Memorial Prize Lecture in Economic Science, 1994. 
Hélio Afonso de Aguilar Filho / Edison Benedito da Silva Filho

NORTH, Douglass C. Institutions and the performance of economies over time. In: MÉNARD, Claude; SHIRLEY, Mary M. (Ed.). Handbook of new institutional economics. Netherlands: Springer, 2005.

PREBISCH, Raul. O desenvolvimento econômico da América Latina e os seus principais problemas. In: BIELCHOWSKY, Ricardo. Cinquenta anos de Pensamento na Cepal. Rio de Janeiro: Record, 2000.

RUTHERFORD, Malcolm. Institutions in economics: the old and the new institutionalism. Nova York: Cambridge University Press, 1999.

SAMUELS, Warren J. The present state of institutional economics. Cambridge Journal of Economics, v. 19, n. 4, p. 569-590, 1995.

STREET, James H.; JAMES, Dilmus D. Institutionalism, structuralism, and dependency in Latin America. Journal of Economic Issues, v. 16, n. 3, p. 673-689, 1982.

SUNKEL, Osvaldo. Institucionalismo y Estructuralismo. Revista de la Cepal, n. 38, p. 147-156, 1989.

VELASCO E CRUZ, Sebastião C. Teoria e história: notas críticas sobre o tema da mudança institucional em Douglass North. Revista de Economia Política, São Paulo, v. 23, n. 90, abr./jun. 2003. 